\title{
Mitochondrial Analysis of Oribatid Mites Provides Insights into Their Atypical tRNAs Annotation, Genome Rearrangement and Evolution
}

\author{
Xuebing Zhan \\ Wannan Medical College \\ Bing Chen \\ Wannan Medical College \\ Yu Fang \\ Wannan Medical College \\ Fangyuan Dong \\ Wannan Medical College \\ Weixi Fang \\ Wannan Medical College \\ Qian Luo \\ Wannan Medical College \\ Lingmiao Chu \\ Wannan Medical College \\ Rui Feng \\ Wannan Medical College \\ Yan Wang \\ Wannan Medical College \\ Xuan Su \\ Wannan Medical College \\ Ying Fang \\ Wannan Medical College \\ Jiaoyang $\mathbf{X u}$ \\ Wannan Medical College \\ Zetao Zuo \\ Wannan Medical College \\ Xingquan Xia \\ Anhui Normal University \\ Jiegen $\mathrm{Yu}$ \\ Wannan Medical College \\ Entao Sun ( $\nabla$ asdentao@126.com ) \\ Wannan Medical College
}

Research

Keywords: Oribatid mites, mitochondrial genome, tRNA re-annotation, phylogeny

Posted Date: November 24th, 2020

DOI: https://doi.org/10.21203/rs.3.rs-112152/v1

License: (c) (i) This work is licensed under a Creative Commons Attribution 4.0 International License. Read Full License

Version of Record: A version of this preprint was published at Parasites \& Vectors on April 23rd, 2021. See the published version at https://doi.org/10.1186/s13071-021-04719-0. 


\section{Abstract}

Background: Mitochondrial (mt) genomes of Sarcoptiformes mites typically contain 37 genes. Loss of genes is rare in Sarcoptiformes mite mt genomes, but two of the six previously reported oribatid mites (Acariform Order Sarcoptiformes) are reported to have lost part of their tRNA genes. To determine whether these tRNA genes were indeed lost and whether the loss of tRNAs is universal, we re-annotated all of the available oribatid mites and sequenced the mt genome of Oribatula sakamorii.

Methods: The mitogenome of $O$. sakamorii was sequenced with lllumina Hiseq sequencer. The mt tRNA gene annotated using multisoftware combined with manual annotation approach. Phylogenetic analyses of maximum likelihood (ML) and Bayesian inference (BI) were performed with both concatenated nucleotide and amino acid sequences.

Results: Mt genomes of $O$. sakamorii contain 37 genes including 22 tRNA genes. We were able to identify all of the mt tRNA genes that were reported as lost in Steganacarus magnus and Paraleius leontonychus, and revealed some atypical tRNAs annotation errors in oribatid mites. Oribatid mite mt genomes are characterized by low rates of gene rearrangement, with six or seven gene blocks conserved between all of the oribatid mite species and the $\mathrm{mt}$ genome of ancestral arthropod. Considering only the relative order of the major genes (PCGs, rRNAs), only one gene or two genes were rearranged relative to the ancestral genome. Both CREx analysis and phylogenetic results supported the origin of the Astigmata within the Oribatida. We also explored the phylogenetic relationships among all of the available oribatid mites and the results also confirm the systematic position of Hermannia in the Crotonioidea superfamily. This is also supported by synapomorphic gene derived boundary.

Conclusions: The tRNA "lost" phenomenon is not universal in oribatid mites. Instead of loss, we found that the highly atypical secondary structure of inferred mt tRNA genes makes them unidentifiable by a single type of tRNA search program. Multi-software combined with manual annotation approach can improve the accuracy of tRNA gene annotation. Besides, we determined the correct systematic position of Hermannia and supported the origin of astigmatid mites was from oribatid mites.

\section{Introduction}

The Oribatida is one of two suborders of Sarcoptiformes. It consists of 56 superfamilies and more than 16,000 species. More than half $(62 \%)$ of mite species in Oribatida are oribatid mites, while the others are astigmatid mites (38\%)[1]. Oribatid mites are an extremely diverse group of mites comprising five supercohorts: The most primitive Palaeosomatides, the early-derived Enarthronotides and Parhyposomatides and the mid-to-highly derived Mixonomatides and Desmonomatides[2]. The supercohort Desmonomatides comprises three cohorts, including Nothrina, Brachypylina and the Astigmata. The true relationship between oribatid mites and astigmatid mites has been controversial. Based on morphological characters, there are three widely established hypotheses: (1) oribatid mites originated from astigmatid mites[3]; (2) both Oribatida and Astigmata are monophyletic sister groups[4-6]; and (3) astigmatid mites originated from oribatid mites[7-10]. Two different classification hypotheses have been proposed for oribatid mites (Family Hermaniidae). Based on morphological characters, Subías et al. considered Hermaniidae to be members of the superfamily Nanhermmanioidea, as part of the Cohort Brachypylina[11]. Norton and Behan-Pelletier suggested that Hermaniidae should be included in the Cohort Nothrina superfamily Crotonioidea[12]. When species classification is controversial and only based on morphology, molecular data are often used to clarify evolutionary and taxonomic problems[13-16]. It is necessary to examine complete mt genomes to study the phylogenetic relationships among oribatid mites.

The mt genome of Sarcoptiformes typically contains a conserved set of 37 genes. Of these, 13 are protein-coding genes (PCGs), 2 rRNAs ( $r r n L$ and rrnS) and 22 are transfer RNA (tRNA) genes. Accurate gene annotation is important because gene orders in mt genomes may contain valuable phylogenetic information. However, identification of tRNAs lacking one or both arms or containing mismatches in the stems is difficult. Such tRNAs may be missed during prediction[17]. Mt genomes of six species of oribatid mites (Order Sarcoptiformes) from two supercohorts (Mixonomatides and Desmonomatides) six families (Phthiracaridae, Crotoniidae, Hermaniidae, Nothridae, Oribatulidae, Scheloribatidae) have been reported previously. In 2008, the first complete mt genome of an oribatid mite, S. magnus was originally described by Domes et al. to exhibit a substantial loss of tRNAs (only 6 of 22 present)[18]. In 2009, Klimov and Oconnor retrieved trnK and re-annotated two tRNAs ((-)-trnW $\rightarrow$ (+)-trnS2, (-)-trnS2 -> (+)-trnW) based on MFE calculations. They refrained the position of trnP described by Domes et al. [19]. In 2011, Edwards et al. used tRNAscan-SE[20] sequence alignments and by manual inspection, identified three of the missing tRNA genes (trnG, trnS1 and trnE) and changed the position of trnP[21]. In 2018, Schäffer et al. re-annotated the tRNAs in $S$. magnus and identified 12 tRNA genes. They also sequenced mt genome of a new oribatid mite, $P$. leontonychus, and found that it lacked two tRNAs ( $\operatorname{trn} G$ and $\operatorname{trn} Y$ ). They considered that tRNA loss did occur in oribatid mites (Order Sarcoptiformes) [17]. Xue et al. did not support the loss of mt tRNA genes in Sarcoptiformes mites including oribatid mites. They retrieved 
all of the 16 tRNAs which were initially reported to be "lost" in S. magnus[22]. Using tRNAscan-SE[20], ARWEN[23] and manual annotation based on anticodon and secondary structures, they found the full set of tRNA genes in four other species of oribatid mites: Oribatula sp., Platynothrus peltifer, Hermannia gibba and Nothrus palustris[24]. The loss of tRNA genes appears to follow no specific rule and there is no consensus about whether mt tRNA genes are really missing in oribatid mites.

In this study, we sequenced the complete mt genome of one oribatid mite (Oribatulidae: $O$. sakamorii). We also re-annotated the mitochondrial tRNA genes in all of the available oribatid mites. Our aims were to: (1) investigate whether tRNAs are really lost in oribatid mites (2) improve the accuracy of atypical tRNAs annotation, and document mt gene rearrangements in the oribatid mites investigated to date, (3) assess whether $\mathrm{mt}$ gene rearrangements show promise as evolutionary and phylogenetic markers in the oribatid mites and (4) explore the phylogenetic relationships of oribatid mites using complete mt genomes.

\section{Results}

\section{General features of $\boldsymbol{O}$. sakamorii mitochondrial genomes}

The mt genome of $O$. sakamorii (GenBank: MT232643) had an overall size of 14,494 bp. It was circular, with 13 PCGs, two ribosomal RNAs (rRNA) and 22 tRNAs and a large non-coding region (Supplementary Table S1). A software search and visual inspection, for $O$. sakamorii, found all of the tRNAs. We detected 21 reliable tRNAs based on online tools including tRNAscan-SE[20], ARWEN[23], MITOS[25] and MITOS2 (http://mitos2.bioinf.uni-leipzig.de). The trnV was identified manually by alignment with their homologue species based on their anticodon and secondary structures (Table 1). The trnF, trnW, trnE and trnK showed a typical cloverleaf structure. The other 18 tRNAs had reduced D-, T-arms or both arms.

The percentage nucleotide composition of the $\mathrm{mt}(+)$-strand is $\mathrm{A}=41.7, \mathrm{C}=18.2, \mathrm{G}=10.9$ and $\mathrm{T}=29.1$, resulted in a positive AT-skew (0.182) and a negative GC-skew (-0.251). A comparative analysis of A + T\% vs AT-skew and G + C\% vs GC-skew among all available mtgenomes of oribatid mites showed six oribatid mites that were together and only $S$. magnus being separated (Fig. 1). This result is consistent with the difference of the supercohort in oribatid mites (Supplementary Table S2).

\section{Re-annotating mitochondrial tRNA genes in oribatid mites}

Numerous methods have varying predictive ability for the atypical secondary structure of tRNAs. For example, tRNAs annotation results for a S. magnus mitochondrial sequence differ when using different type and/or numbers of tRNA predictive methods (Fig. 2). In the present study, we applied all available tRNA prediction methods designed to maximize the accuracy of tRNA genes annotation, especially for atypical tRNAs. We confirmed the prediction of the majority of tRNAs with previous described ones. All of the "lost" tRNA genes in oribatid mites were found and some of the incorrectly annotated tRNAs were re-annotated (Fig. 2). The details are as follows:

The re-annotation of the tRNAs of the $O$. sp. predicted three tRNAs based on its mitogenome(GeneBank: MH921998), including $t r n Y$, trnS1 and $t r n M[24]$. ARWEN[23] predicted $\operatorname{trn} Y$ is situated between $\operatorname{trn} Q$ and $\operatorname{trn} P$ and previously retrieved $\operatorname{trn} Y$ is situated between $\operatorname{trn} C$ and $n a d 2$ (Fig. 2). The trnS1 was found by MITOS2, encoded on the (+)-strand at the 3'end of $t r n L 1$. In contrast, previously described trnS1 was identified on the (-)-strand at the 3 'end of $\operatorname{trn} Q$ (Fig. 2). The trnM could be identified manually by sequence alignment and secondary structure comparison with those identified in other species of oribatid mites (Table 1). To select the most probable tRNAs, the minimum free energy (MFE) was calculated[26]. The MFE for this study described three tRNA structures that are smaller than those seen in previous study (Fig. 3). The secondary structure of our described tRNAs has fewer mismatches in the acceptor or/and anticodon stem (Fig. 3).

By multiple sequence alignment analysis (Table 1), we manually identified two "lost" tRNAs (trnG and trnY) in Pa. leontonychus[17]. The $\operatorname{trn} G$ was identified on the (+)-strand at the $3^{\prime}$ end of cox3, $\operatorname{trn} Y$ was identified on the (-)-strand at the 3 'end of $\operatorname{trn} Q$ (Fig. 2). MFE value and secondary structure of $\operatorname{trn} G$ and $\operatorname{trn} Y$ are shown in Fig. 3. We also re-annotated trnA, trnS1 and trnC for Pl. peltifer, trnS1 and trnY for $H$. gibba based on manual sequence annotation (Fig. 2). MFE for these tRNA structures are all smaller than described by Xue et al.[24] (Fig. 3). The secondary structure of our described tRNAs also has fewer mismatches in the acceptor and/or anticodon stem (Fig. 3). 
Table 1

The alignment of nucleotide sequences of 4 mitochondrial tRNA genes ( $\operatorname{trn} V, \operatorname{trn} M, \operatorname{trn} G$ and $\operatorname{trn} Y)$ of the same superfamily in oribatid mites.

\begin{tabular}{|c|c|c|c|c|c|c|}
\hline \multirow[t]{3}{*}{$\operatorname{trn} V$} & O. sakamorii & TTAGGGT & --TTA--TTTTT & CTTTAATTACGGTAAAG & $\begin{array}{l}\text { A-TG- } \\
\text { TTTTT }\end{array}$ & $\begin{array}{l}\text { AACC- } \\
\text { TTAG }\end{array}$ \\
\hline & O. $s p$. & $\overline{\text { GTTGGG }}$ & GCTTTTCTTTTGAGAT & TTTTATTTACGGTAAAA & $\begin{array}{l}\text { ATTTG- } \\
\text { TCTGC }\end{array}$ & $\begin{array}{l}\text { CCTAAC-- } \\
\text { TT }\end{array}$ \\
\hline & $\begin{array}{l}\text { Pa. } \\
\text { leontonychus }\end{array}$ & $\begin{array}{l}\text { AGA- } \\
\text { GTTT }\end{array}$ & --TGG-TTCC & CTTTAATTACGGTAAAG & GT-TGGTGT & $\overline{\text { TAACTCTT }}$ \\
\hline \multirow[t]{3}{*}{$\operatorname{trnM}$} & O. sakamorii & -AGCAAGT & - AAAGCTTAATT-- AAGCTT & AGGTATTCATAATTCCT & AGAATTT & CATTGCTA \\
\hline & O. $s p$. & T-AGTAAA & C AAAGCTTAACCACAAAGCTT & AGGTATTCATAATTCCT & AGAAATTGA & A-TTACTAG \\
\hline & $\begin{array}{l}\text { Pa. } \\
\text { leontonychus }\end{array}$ & - & - AAAGCTTAAATA- AAGCTT & AGGTATTCATAATTCCT & AGAACAAC & CGTTGCTC \\
\hline \multirow[t]{3}{*}{$\operatorname{trn} G$} & O. sakamorii & AT- TCTTA & TAG- TATATGTC- - --GT- ACA & - TTTAATTTCCAATTAAA & AAG-AAA & AAAGAAAA \\
\hline & O. $s p$. & ATTTCA-A & CAG-TATACAAA- - - GT- ACG & C-TTAATTTCCAATTAAG & AAG-AAAA & $\begin{array}{l}\text { AA- } \\
\text { GAAACA }\end{array}$ \\
\hline & $\begin{array}{l}\text { Pa. } \\
\text { leontonychus }\end{array}$ & AA-TCTTA & AAAATTAAAAGGTAAAGTTAAAT & $\overline{\text { TAAAATTTCCATTCTGT }}$ & GAGTCACAGC & TTT GATAC \\
\hline \multirow[t]{3}{*}{$\operatorname{trn} Y$} & O. sakamorii & $\begin{array}{l}\text { TTTGA- } \\
\text { GG }\end{array}$ & TGATTACGCAT- A & AGAAA-TTGTAAA-TTTCT & TTTTTT- T & $\begin{array}{l}\text { TA- } \\
\text { TCAAAT }\end{array}$ \\
\hline & O. $s p$. & $\begin{array}{l}\text { TTT- } \\
\text { ACGG }\end{array}$ & TGA - GATTGGA & AGAAA-TTGTAAA-TTTCT & ATTTTTTTAT & $\begin{array}{l}\text { CA - } \\
\text { TTATAT }\end{array}$ \\
\hline & $\begin{array}{l}\text { Pa. } \\
\text { leontonychus }\end{array}$ & $\begin{array}{l}\text { TTT- } \\
\text { AGGG }\end{array}$ & TGAAAA-GCAAA- A & ' & - TTTGCAAAT & CGGTGTAA \\
\hline
\end{tabular}

Note: The anticodons are bold text. The conserved sequences are in underlined letters.

The $S$. magnus mitochondrial gene annotation is controversial. In this study, we confirmed the prediction of 18 tRNAs made in previous studies and were-annotated four tRNAs including $\operatorname{trn} P, \operatorname{trn} L 1, \operatorname{trnN}$ and $\operatorname{trnF}$ (Fig. 2). The position of $\operatorname{trn} P$ is still uncertain. Such Klimov and Oconnor and Schäffer et al. didn't re-annotate $\operatorname{trn} P$ (Fig. 2). Xue et al. refrained the trnP which were inferred by Edwards et al. in $S$. magnus and they confirmed the $\operatorname{trn} P$ which were inferred by Domes et al.[22]. Based on manual annotation, $\operatorname{trn} P$ was found on the sequence of $\operatorname{trn} Q \sim \operatorname{trn} W$ (on the (-) -strand) (Fig. 2). Compared to previous studies describing $\operatorname{trn} P$, the structure of $\operatorname{trn} P$ in this study is more stable thermodynamically (Fig. 3). The secondary structure of $t r n L$, predicted by Xue et al. has five mismatches in the anticodon stem (Fig. 3) [22]. The $\operatorname{trn} L 1$, which was suggested by Schäffer et al. has two mismatches in the anticodon stem[17]. We proposed that $\operatorname{trn} L 1$ has 1 mismatch in the anticodon stem, indicating it may be a more stable structure (Fig. 3). Our trnL 1 also preserves the Limulus polyphemus gene order $\operatorname{trn} L 2$-trnL 1 (Fig. 2). The trnN could be inferred manually in this study. MFE values were smaller in our analyses compared to Xue et al.[22]. This indicates that our version of $t r n N$ structure may be more stable. Based on anticodon and secondary structures, we manually identified that $t r n F$ is located between the $\operatorname{trn} N$ and $\operatorname{trn} Y$ genes (Fig. 2), while Xue et al. described one overlap with the first position of an upstream gene (39 bp)[22] and this may violate the tRNA punctuation model for RNA processing[27].

\section{Codon usage in the mt genomes of oribatid mites}

We analyzed the codon usage in the mt PCGs of the seven species of oribatid mites to determine whether the corresponding codons of the "lost" tRNA genes are used. To avoid bias due to unusual putative start codons and incomplete stop codons, all of the first codons as well as stop codons were excluded from the analysis. Codons for all of the 22 amino acids are present in all of the PCGs in all of the oribatid mites, including the two species in which mt tRNA gene "loss" has been reported (Fig. 4). The amino acid frequencies are similar in the seven different oribatid mites. The codon families also exhibited a similar pattern among them.

\section{Common-interval analysis of Sarcoptiformes gene order with CREx}

We calculated the common interval with CREx as a measure of the extent of $\mathrm{mt}$ genome reorganization (Table 2). According to the number of common intervals, the gene orders of the major genes (PCGs and rRNAs) were used to infer the possible evolutionary relationships within oribatid mites, astigmatid mites and the putative ancestral arthropod (L. polyphemus) (Fig. 5). By comparing the gene 
order of type I with L. polyphemus, nad2 was found to be a transposition. By comparing the gene order of type II with the type I, nad1 was found to be a transposition. By comparing the gene order of type III with the type II, three rearrangement events were inferred: transposition of one gene block (cob and nad2), reverse transposition of two genes (nad1 and rrnL) and four reversals in a large gene block (Fig. 5).

Table 2

The number of common intervals of L. polyphemus, oribatid mites and astigmatid mites when mitochondrial major gene (PCGs and rRNAs) arrangements are compared.

\begin{tabular}{|lllll|}
\hline & L. polyphemus & Six oribatid mites & S. magnus & astigmatid mites \\
\hline L. polyphemus & 204 & 154 & 132 & 56 \\
\hline Six oribatid mites & 154 & 204 & 154 & 204 \\
\hline S. magnus & 132 & 154 & 60 & 204 \\
\hline astigmatid mites & 56 & 56 & 20 \\
\hline $\begin{array}{l}\text { Note: Six oribatid mites including H. gibba, N. palustris, O. sp, O. sakamorii, Pl. peltifer and Pa. leontonychus share a same gene (PCGs } \\
\text { and rRNAs) order. All available astigmatid mites share a same gene (PCGs and rRNAs) order. }\end{array}$ \\
\hline
\end{tabular}

\section{Mapping shared gene orders in oribatid mites}

Linearized gene order maps for seven oribatid mite mt genomes plus the ancestral arthropod gene order are given in Fig. 6 . The mt genome of oribatid mites are rearranged compared to the hypothetical ancestor of arthropods, represented by $L$. polyphemus. The seven oribatid mite species from six families have rearranged $\mathrm{mt}$ genomes. Each species has a unique mt genome organization (Type I to Type VII, Fig. 6). Seven ancestral gene blocks consist of between two and eight genes (1-7 gene boundaries) (Fig. 6). Gene block A (cox1-cox2) and block $\mathrm{F}$ (trnt-trnQ) are conserved in all seven oribatid mites. Gene block B (trnD-atp8-atp6-cox3-G-nad3-trnA) is retained in all of the oribatid mite species except $P$. peltifer and $N$. palustris. Block C (trnS1-trnE-trnF-nad5-trnH-nad4-nad4l-trnT) is only conserved in H. gibba and $\mathrm{Pl}$. peltifer, and partially present in the other five oribatid mites. Gene block D (nad6-cob-trnS2-nad1) is retained in all of the oribatid mite species except $S$. magnus where trnR inserted between cob and trnS2, and nad1 is a translocation. Block $F$ (rrnL-trnV-rrnS) and block $\mathrm{G}(\operatorname{trn} W$-trnC) are also conserved in all oribatid mite species except $S$. magnus.

One hundred and twenty-nine derived gene boundaries were found in the seven available mt genomes of oribatid mites (numbered 1 to 56 in Fig. 6). Of these, 19 are shared, derived gene boundaries present in at least two species and an additional 37 unique boundaries found in a single species were identified (Fig. 6). Gene boundaries (2, 4, 6-8 and 11-21) were only found in S. magnus. Gene boundaries (24$26,28,34,35$ and 37 ) were only found in $P a$. leontonychus. Gene boundaries (39 and 40) were only found in $0 . s p$. Gene boundary (43) was only found in 0 . sakamorii. Gene boundaries (43-50) were only found in N. palustris. Gene boundaries (54 and 55) were only found in Pl. peltifer. Gene boundary (56) was only found in H. gibba.

Out of the 19 derived gene boundaries, 11 were either homoplastic or secondarily lost in some of the taxa descended from the node and remaining 8 are unambiguous synapomorphies. Hence, eight shared derived gene boundaries were mapped onto the phylogenetic tree inferred from the ML dataset (Fig. 7). Five derived gene boundaries (27 and 29-32) are synapomorphies supercohort Desmonomatides (Type II to Type VII Fig. 6). Gene boundary 41 (trnE-trnK) is a synapomorphy for the family Oribatulidae (Type III and Type IV Fig. 6). Gene boundary 33 (trnR-trnE) is a synapomorphy for the superfamily Oripodoidea (Type II to Type IV Fig. 6), whereas boundary 53 (trnR-trnK) is a synapomorphy for H. gibba and PI. peltifer (Type VI to Type XVII Fig. 6).

\section{Phylogenetic relationships}

We constructed a phylogenetic tree based on a nucleotide data set from $13 \mathrm{mt} \mathrm{PCGs} \mathrm{of} 59$ mites (Fig. 8). The ML and BI analyses showed similar topologies. Monophyly of Oribatida is recovered with strong support (BPP = 1, BSP = 100; Fig. 8), as well as monophyly of Desmonomatides. The monophyly of Astigmata (astigmatid mites) is recovered with support (BPP = 0.99, BSP = 71). Within Desmonomatides, six oribatid mites from two superfamilies (Crotonioidea and Oripodoidea) of two cohorts (Nothrina and Brachypylina) formed a monophyletic clade; each of the superfamilies or cohorts is monophyletic with strong support $(\mathrm{BPP}=1, \mathrm{BSP}=100)$. Here the phylogeny of Desmonomatides at the cohort level is suggested as (Astigmata, (Nothrina, Brachypylina)). The new sequence of $O$. sakamorii showed a sister-group relationship with the $0 . s p$. (BPP $=0.97$, BSP $=49 ;$ Fig. 8$)$. The phylogenetic tree shows that $H$. gibba and Pl. peltifer cluster into one branch with strong support (BPP = 1, BSP = 96; Fig. 8). 


\section{Discussion}

The tRNA genes encoded by mt genomes are critical to the mitochondrial translation system. Loss of any of the 22 tRNA genes will severely affect the translation system in mitochondria unless a nuclear equivalent can be imported into the mitochondria. Therefore, Xue et al. did not support the loss of any mt tRNA genes in Sarcoptiform mites[22]. Fang et al. also did not support tRNA loss. After de novo sequencing and analysis of the circular $\mathrm{mt}$ genome of Tyrophagus putrescentiae, they retrieved three tRNA ( $\operatorname{trn} F$, $\operatorname{trnS} 1$, trnQ) genes that previous studies were "lost"[28]. We identified all of the "lost" tRNAs in oribatid mites. In addition, the overall codon usage was found to be very similar across all available oribatid mites. Therefore, our results do not support the loss of any of the 22 tRNA genes in oribatid mites.

Accurate annotation is necessary to understand the degree of rearrangement within a species. However, identification of tRNAs lacking one or both arms or containing mismatches in the stems is challenging[17]. In addition, different annotation methods can affect the results of sequence annotation[29]. Improving the accuracy of gene annotation will benefit downstream users of these gene sequences. We corrected incorrect annotation of atypical tRNAs in all of the reported oribatid mite sequences using multi-software combined manual annotation approach.

The relationship between oribatid mites and astigmatid mites has been controversial. No previous studies have evaluated the relationship between oribatid mites and astigmatid mites based on major genes. Mitochondrial rearranged gene order will help clarify the relationship between oribatid mites and astigmatid mites. Limiting our CREx analysis to just the major genes (PCGs and rRNAs) and removing tRNAs have aided understanding of the major genomic evolutionary events within the Metazoa. This is because the higher relative rates of rearrangement obscured the fundamentally conserved nature of gene arrangement across taxa[25]. Therefore, using major genes, we mapped possible evolutionary processes within Sarcoptiformes mites (Fig. 6). Our results supported that the origin of astigmatid mites was from oribatid mites.

Oribatid mite mt genomes are marked by low rates of gene rearrangement, with six or seven gene blocks conserved between any oribatid mite species and the ancestral arthropod mt genome. Considering only the relative order of the major genes (PCGs, rRNAs), only one gene or two genes were rearranged relative to the ancestral genome. But the ancestral mitochondrial gene order features in Oribatid mites have not been determined as taxa representing basal species of this suborder have not been identified[6]. However, the conserved gene block $E$ $((-)$ rrnL- (-) trnV- (-) rrnS), which preserves the L. polyphemus gene order, has been found in six oribatid mites. Thus, the hypothetical ancestor of Acariformes mites might also retain this conserved gene block. This result amends Xue et al. hypothesis about the ancestral gene order of Acariformes[30].

Through mapping derived gene boundaries, we identified several that were synapomorphic for major clades within oribatid mites and that provided supporting evidence for the consensus phylogenetic topology. For example, trnR-trnK (derived boundary \#53) is synapomorphic for H. gibba and Pl. peltifer, and the systematic position of Hermannia had been viewed differently in pervious morphological classification[11, 12]; trnE-trnK (derived boundary \#41) is synapomorphic for Oribatulidae increasing our confidence in clades for which nodal support is weak (Fig. 7).

Inferring "true" phylogenetic affinities and classification within the Acariformes has been difficult. Consistent with results based on gene order inference, our phylogenetic reconstruction based on 13 PCGs inferred the origin of Astigmata within Oribatida. It is problematic to establish the correct systematic position of Hermannia in the Crotonioidea superfamily on the basis of morphology alone[31]. Our phylogenetic tree showed that $H$. gibba and Pl. peltifer are clustered into one branch with strong support (BPP = 1, BSP = 96; Fig. 4). Further mt genome sequencing of oribatid mites in the Crotonioidea superfamily will be necessary to clarify the systematic position of Hermannia.

\section{Conclusions}

We used multi-software combined with manual annotation approach to identify all of the mt tRNA genes, which were previously reported as "lost" in oribatid mites. The mt tRNA genes previously reported as "lost" were located. They have unusual secondary structures and contain many nucleotide mismatches on their arms. The newly sequenced mitogenome of $O$. sakamorii has important ramifications for our understanding of tRNAs. The "lost" phenomenon is not universal in oribatid mites. We determined the correct systematic position of Hermannia and supported the origin of astigmatid mites was from oribatid mites. Derived gene boundaries of oribatid mites can provide a valuable source of information for understanding oribatid mite phylogeny and evolution. However, in-depth data on more taxa of oribatid mites, including species from each of the five supercohorts, could enhance our knowledge of rearrangements and other evolutionary events. 


\section{Material And Methods \\ Mite collection and DNA extraction}

Specimens of 0 . sakamorii were collected from soil in a Wuhu park on October 6, 2019, and preserved in alcohol. Mite samples were preserved at $-20^{\circ} \mathrm{C}$ before DNA extraction. Mites were identified as 0 . sakamorii based on morphology. To confirm identification, molecular techniques were applied. We used Clustal X2.0[32] to compare the region of mitochondrial DNA sequences containing the 18S rRNA genes to those of the previously identified 0 . sakamorii with GenBank accession numbers AB818530.1. All of the specimens were deposited in Wannan Medical College. Approximately 1000 adult mites were ground and total genomic DNA was extracted using phenolchloroform[33].

\section{Mitochondrial genome sequencing, assembly}

Sequencing libraries were prepared by Shanghai BIOZERON Company (China) (http://www.biozeron.com/). O. sakamorii genomic DNA was fragmented into 300-500 bp by Covaris M220. The genomic library (430 bp) was constructed by the utilization of TruSeq ${ }^{\text {TM }}$ DNA Sample Prep Kit. Bridge PCR was performed according to the manufacturer's instructions, using the Hiseq PE Cluster Kit v3 cBot (IIlumina) and then sequenced on the Illumina Hiseq 4000[34]. Prior to assembly, raw reads were filtered firstly. This filtering step was performed in order to remove the reads with adaptors. The reads showed a quality score below $20(\mathrm{Q}<20)$ containing a percentage of uncalled based ("N" characters) equal or greater than $10 \%$ and the duplicated sequences. Clean reads were assembled using SOAPdenovo v2.04(http://soap.genomics.org.cn/)[35]. Then, we used GapCloser v1.12 software[https://sourceforge.net/projects/soapdenovo2/files/GapCloser/[to perform local cavity filling and base correction on the assembly results.

\section{Mitochondrial genome annotation and analysis}

Using MITOS2 (http://mitos2.bioinf.uni-leipzig.de) and MEGA software[36], protein-coding genes (PCGs) were identified. The two rRNA genes, rrnL and rrnS, were identified by BLASTn searches of NCBI based on highly conserved sequence motifs. However, the 5 'and 3 'ends of rrnL and rrnS cannot be determined with accuracy. We tentatively annotated the 5 'ends of these genes immediately following the 3 'ends of the upstream gene and the 3'ends of the rRNAs to be immediately before the downstream gene, with no gaps in between[24]. Different prediction methods have variable predictive ability. Owing to the atypical secondary structure of tRNAs, we applied available tRNA prediction methods including tRNAscan-SE[20], ARWEN[23], MITOS[25] and MITOS2 (http://mitos2.bioinf.uni-leipzig.de) and manual annotation. Our goal was to maximize the accuracy of gene annotation. Manual annotation is based on comparing nucleotide sequences of conserved regions (anticodon loop and anticodon arm) and/or by sequence alignment with their homologues in related species. MFE was calculated for these structures (constrained analysis) in RNAfold[26]. The secondary structure of tRNA with the smallest constrained MFE was considered to be the most likely one[17].

The nucleotide composition, codon usages, relative synonymous codon usage (RSCU) were done by MEGA. To calculate the skewness, we used the formula, as AT skew $=(A-T) /(A+T)$ and $G C$ skew $=(G-C) /(G+C)$, respectively [37].

\section{Gene rearrangement analyses and phylogenetic analysis}

CREx was used to conduct common interval analysis[38]. Pairwise comparisons using CREx were performed for all available oribatid mites and the presumed ancestral arthropod ancestral L. polyphemus major mt genes (PCGs and rRNAs) to determine the minimum number of genome rearrangement events separating each of these mite species from the "recently ancestral" state. CREx considers three types of rearrangement events: transpositions, reverse transpositions and reversal. We mapped the gene boundaries on the gene order to determine the unique, derived and ancestral gene boundaries between the ancestral arthropod L. polyphemus and the other taxa of oribatid mites[39].

The complete mt genome sequences of 57 species of Arachnida and two Xiphosura species were retrieved from GenBank (Supplementary Table S2). The outgroup includes 13 species belonging to 12 different orders, i.e. Xiphosura, Amblypygi, Araneae, Opiliones, Pseudoscorpiones, Ricinulei, Scorpiones, Solifugae, Thelyphonida, Holothyrida, Ixodida and Mesostigmata. The nucleotide sequences of the PCGs were aligned individually by Mafft v7v.7.035[40] with Codon and Protein strategy, respectively; large gaps and ambiguous sites were deleted by Gblocks v.0.91b[41] with G-INS-i strategy for global homology and manually inspected before concatenation. The third codon of the aligned nucleotide sequences was additionally removed by MEGA6[36] for eliminating random or swinging sites. Three datasets were separately concatenated from the alignments of individual genes (13 whole-codoning nucleotide sequences, 13 excluded- 
third-codoning nucleotide sequences, and 13 amino acid sequences) in GENEIOUS v5.4[42]. Phylogenetic analyses were conducted using maximum likelihood (ML)[43]and Bayesian inference (BI)[44] methods.

Dataset partitioning was performed by PartitionFinder, based on an initial total of 39 data blocks (nucleotide sequences, 13 PCGs by three codon positions and 13 PCGs by the first and second codon positions; and amino acid sequences, 13 PCGs). Each type of partitioned nucleotide sequence was run twice independently. Models were predicted by PartitionFinder v .2.1.1[45], using the Bayesian information criterion (BIC). PartitionFinder used unlinked branch lengths, the greedy search algorithm for nucleotide sequences and RAxML models. For the dataset of whole-codoning nucleotide sequences, the substitution model GTR $+\mathrm{I}+\mathrm{G}$ was chosen by PartitionFinder as the best for fourteen of the twenty partitions, the GTR $+\mathrm{G}$ models for the remaining six partitions (Supplementary Table S3). For the dataset of excluded-third-codoning nucleotide sequences, the best substitution model GTR $+\mathrm{I}+\mathrm{G}$ was chosen by PartitionFinder for all eight partitions (Supplementary Table S3). For the dataset of amino acid sequences, the substitution model $L G+I+G$ was chosen by PartitionFinder as the best for five of the seven partitions, the $L G+G$ models for the remaining two partitions (Supplementary Table S3).

$\mathrm{BI}$ analyses were performed in MrBayes v.3.2.2[44]. For the two datasets of nucleotide sequences, we used separate data partitions models and conducted two independent runs each with four Markov chains Monte Carlo (one cold chain and three heated chains). Each of the two datasets was run for 20 million generations, with trees sampled every 1000 generations. The convergence of the parameter estimates was performed with TRACER v.1.6. A conservative burn-in of $25 \%$ was then applied. All estimated parameters showed ESS values above 200. For the dataset of amino acid sequences, $\mathrm{BI}$ analyses were too performed with MrBayes and the same process, but using a fixed (wag) model and running 10 million generations. The consensus tree, supported by Bayesian posterior probabilities (BPP) $\geq$ 95\%, was edited with FigTree v.1.4.0. Nodes, which was considered strongly supported[46].

ML analyses were performed in the RAxML-7.035, using the GTRGAMMAI model for nucleotide sequences and the PROTGAMMAWAG model for amino acid sequences. Clade support was assessed using a nonparametric bootstrap with 1000 replicates. The consensus tree, supported by bootstrap values (BSP) $\geq 70 \%$, was edited with FigTree v.1.4.0. Nodes, which was considered strongly supported[47].

\section{Abbreviations}

atp6 and atp8: Genes for ATP synthase subunits 6 and 8; bp: Base pair; cob: Gene for cytochrome b; cox1, cox2, and cox3: Genes for cytochrome coxidase subunits 1, 2 and 3; CR: Control region; DNA: Deoxyribonucleic acid; RNA: Ribonucleic Acid; mt: mitochondrial; nad1 and nad2: Mitochondrial genes for NADH dehydrogenase subunits 1 and 2; PCGs: Protein-coding genes; PCR: Polymerase chain reaction; rRNA: Ribosomal RNA; rrnS and rrnL: Genes for small and large subunits of ribosomal RNA; RSCU: Relative Synonymous Codon Usage; $\operatorname{trn} A$ : tRNA gene for alanine; tRNA: Transfer RNA; trnC. tRNA gene for cysteine; trnD: tRNA gene for aspartic acid; trnE: tRNA gene for glutamic acid; trnF: tRNA gene for phenylalanine; trnG: tRNA gene for glycine; trnH: tRNA gene for histidine; trnl: tRNA gene for isoleucine; trnK: tRNA gene for lysine; $\operatorname{trn} L 1$ : tRNA gene for leucine; $\operatorname{trn} L 2$ : tRNA gene for leucine; $\operatorname{trnM}$ : tRNA gene for methionine; trnN: tRNA gene for asparagine; $t r n P$. tRNA gene for proline; $t r n Q$ : tRNA gene for glutamine; $t r n R$ : tRNA gene for arginine; $t r n S 1$ : tRNA gene for serine; trnS2: tRNA gene for serine; $\operatorname{trn} T$ : tRNA gene for threonine; $\operatorname{trn} V$ : tRNA gene for valine; trnW: tRNA gene for tryptophan; trnY: tRNA gene for tyrosine; MFE: the minimum free energy; bp: base pair; ML: Phylogenetic analyses of maximum likelihood; BI :Bayesian inference

\section{Declarations}

\section{Ethics approval and consent to participate}

No specific permits were required for the mites collected for this study in China. The mite specimens were collected from park, and the field studies did not involve endangered or protected species. The species in our study are common mites and are not included in the "List of Protected Animals in China".

\section{Consent for publication}

Not applicable.

\section{Availability of data and materials}

The datasets generated and/or analysed during the current study are not publicly available due [the mt genomes of $O$. sakamorii submitted on GenBank under the accession number MT232643, and not released yet] but are available from the corresponding author on reasonable request. 


\section{Competing interests}

The authors declare that they have no competing interests.

\section{Funding}

This research was funded by the Natural Science Foundation of China (No. 31870352), the Foundation for Key Project of Natural Science Research Education Department of Anhui Province (grant no. KJ2017A249), and the Youth Talent Support of Wannan Medical College (No. wyqnyx201902). The founding bodies had no role in the design of the study and collection, analysis, and interpretation of data and in writing the manuscript.

\section{Author Contributions}

X.B.Z. conceived and wrote the manuscript; B.C., Yu F., F.Y.D., W.X.F., L.Q., L.M.C. and R.F. prepared the figures and data, and analyzed the data; Y.W., X.S., Ying F., J.Y.X. and Z.T.Z. contributed to discussions during the data analyses X.Q.X. did the phylogenetic analyses E.T.S. and J.G.Y. conceived the study and revised the manuscript.

\section{Acknowledgements}

We are deeply indebted to Dr Liu Dong (Key Laboratory of Wetland Ecology and Environment, Northeast Institute of Geography and Agroecology, Chinese Academy of Sciences) for this help in species identification. We also thank LetPud (www.letpub.com) for its linguistic assistance during the preparation of this manuscript.

\section{References}

1. Z. Q. Zhang. Animal biodiversity: An outline of higher-level classification and survey of taxonomic richness. Magnolia Press; 2011.p.1-55.

2. E. E. Lindquist, G. W. Krantz and D. E. Walter. In A Manual of Acarology. (eds Krantz, G. W . \& Walter, D. E.). Texas Tech University Press, Lubbock; 2009.p.97-103.

3. A. C. Oudemans. Studie over de sedert 1877 ontworpen systemen der Acari; nieuwe classificatie; phylogenetische beschouwingen. Tijdschrift voor entomologie.1923; 66:49-85.

4. E. W. Baker, R. E. Crabill and G. Nunes. Guide to the families fo mites. Southwestern Naturalist.1958; 3:238.

5. T. A. Woolley. A Review of the Phylogeny of Mites. Annual Review of Entomology.1961; 6:263-284.

6. K. Domes, M. Althammer, R. A. Norton, S. Scheu and M. Maraun. The phylogenetic relationship between Astigmata and Oribatida (Acari) as indicated by molecular markers. Experimental and Applied Acarology.2007; 42:159-171.

7. R. A. Norton. Morphological evidence for the evolutionary origin of Astigmata (Acari: Acariformes). Experimental and Applied Acarology.1998; 22:559-594.

8. M. Dabert, W. Witalinski, A. Kazmierski, Z. Olszanowski and J. Dabert. Molecular phylogeny of acariform mites (Acari, Arachnida): strong conflict between phylogenetic signal and long-branch attraction artifacts. Molecular Phylogenetics and Evolution.2010; 56:222-241.

9. A. R. Pepato and P. B. Klimov. Origin and higher-level diversification of acariform mites - evidence from nuclear ribosomal genes, extensive taxon sampling, and secondary structure alignment. BMC Evolutionary Biology.2015; 15:178-178.

10. P. B. Klimov, B. M. Oconnor, P. E. Chetverikov, S. J. Bolton, A. R. Pepato, A. L. Mortazavi, et al.R. Ochoa. Comprehensive phylogeny of acariform mites (Acariformes) provides insights on the origin of the four-legged mites (Eriophyoidea), a long branch. Molecular Phylogenetics and Evolution.2018; 119:105-117.

11. L. S. Subías, U. Shtanchaeva and A. Arillo. Listado de los acaros oribatidos(Acariformes, Oribatida) de las diferentes regiones biogeograficas del mundo. Monografías electronicas de la Sociedad Entomologica Aragonesa.2012; 4:1-815.

12. R. A. Norton and V. M. Behan-Pelletier. Suborder Oribatida. In: Krantz, G.W.,Walter, D.E. (Eds.). Texas Tech University Press, Texas; 2009.p.430-564.

13. P. Schaap, T. Winckler, M. Nelson, E. Alvarezcurto, B. Elgie, H. Hagiwara, et al.T. Dingermann. Molecular Phylogeny and Evolution of Morphology in the Social Amoebas. Science.2006; 314:661-663.

14. R. Schelly, W. Salzburger, S. Koblmüller, N. Duftner and C. Sturmbauer. Phylogenetic relationships of the lamprologine cichlid genus Lepidiolamprologus (Teleostei: Perciformes) based on mitochondrial and nuclear sequences, suggesting introgressive hybridization. 
Molecular Phylogenetics and Evolution.2006; 38:426-438.

15. A. Petrusek, A. Hobaek, J. P. Nilssen, M. Skage, M. Cerný, N. Brede and K. Schwenk. A taxonomic reappraisal of the European Daphnia longispina complex (Crustacea, Cladocera, Anomopoda). Zoologica Scripta.2008; 37:507-519.

16. A. J. Harris, Q. Xiang and D. T. Thomas. Phylogeny, origin, and biogeographic history of Aesculus L. (Sapindales) - an update from combined analysis of DNA sequences, morphology, and fossils. Taxon.2009; 58:108-126.

17. S. Schäffer, S. Koblmüller, I. Klymiuk and G. G. Thallinger. The mitochondrial genome of the oribatid mite Paraleius leontonychus: new insights into tRNA evolution and phylogenetic relationships in acariform mites. Scientific Reports.2018; 8:7558.

18. K. Domes, M. Maraun, S. Scheu and S. L. Cameron. The complete mitochondrial genome of the sexual oribatid mite Steganacarus magnus: genome rearrangements and loss of tRNAs. BMC Genomics.2008; 9:532.

19. P. B. Klimov and B. M. Oconnor. Improved tRNA prediction in the American house dust mite reveals widespread occurrence of extremely short minimal tRNAs in acariform mites. BMC Genomics.2009; 10:598-598.

20. P. Schattner, A. Brook and T. Lowe. The tRNAscan-SE, snoscan and snoGPS web-servers for the detection of tRNAs and snoRNAs. . Nucleic Acids Research.2005; 33:686-689.

21. D. D. Edwards, L. E. Jackson, A. J. Johnson and B. R. Ernsting. Mitochondrial genome sequence of Unionicola parkeri (Acari: Trombidiformes: Unionicolidae): molecular synapomorphies between closely-related Unionicola gill mites. Exp Appl Acarol.2011; 54:105-17.

22. X. Xue, W. Deng, S. Qu, X. Hong and R. Shao. The mitochondrial genomes of sarcoptiform mites: are any transfer RNA genes really lost? BMC Genomics.2018; 19:466.

23. D. Laslett and B. Canback. ARWEN: a program to detect tRNA genes in metazoan mitochondrial nucleotide sequences. Bioinformatics.2007; 24:172-175.

24. W.-N. Li and X.-F. Xue. Mitochondrial genome reorganization provides insights into the relationship between oribatid mites and astigmatid mites (Acari: Sarcoptiformes: Oribatida). Zoological Journal of the Linnean Society.2019; 187:585-598.

25. M. Bernt, A. Donath, F. Juhling, F. Externbrink, C. Florentz, G. Fritzsch, et al.P. F. Stadler. MITOS: improved de novo metazoan mitochondrial genome annotation. Molecular Phylogenetics and Evolution.2013; 69:313-319.

26. Ronny Lorenz, Stephan H Bernhart, Christian Höner zu Siederdissen, Hakim Tafer, Christoph Flamm and P. F. S. a. I. L. Hofacker. ViennaRNA Package 2.0. Algorithms for Molecular Biology.2011; 6:26-39.

27. D. Ojala, J. Montoya and G. Attardi. tRNA punctuation model of RNA processing in human mitochondria. Nature.1981; 290:470-474.

28. W. Fang, F. Dong, E. Sun, D. Tao, Y. Wang, J. Xu, et al.C. Ye. De novo sequence of the mitochondrial genome of Tyrophagus putrescentiae (Acari: Sarcoptiformes) including 22 tRNA sequences and the largest non-coding region. Experimental and Applied Acarology.2020; 80:521-530.

29. S. L. Cameron. How to sequence and annotate insect mitochondrial genomes for systematic and comparative genomics research. Systematic Entomology.2014; 39:400-411.

30. X. Xue, J. Guo, Y. Dong, X. Hong and R. Shao. Mitochondrial genome evolution and tRNA truncation in Acariformes mites: new evidence from eriophyoid mites. Scientific Reports.2016; 6:18920-18920.

31. S. Seniczak, A. Seniczak and S. J. Coulson. Morphological ontogeny, distribution and descriptive population parameters of Hermannia reticulata (Acari: Oribatida: Hermanniidae), with comments on Crotonioidea. International Journal of Acarology.2017; 43:52-72.

32. M. A. Larkin, G. Blackshields, N. P. Brown, R. Chenna, P. A. McGettigan, H. McWilliam, et al.D. G. Higgins. Clustal W and Clustal X version 2.0. Bioinformatics.2007; 23:2947-2948.

33. S. Zhang and A. S. Alvarado. Planarian High Molecular Weight DNA Isolation by Spooling. Methods Mol Biol.2018; 1774:277-284.

34. E. Borgstrom, S. Lundin and J. Lundeberg. Large scale library generation for high throughput sequencing. PLOS ONE.2011; 6.

35. R. Luo, B. Liu, Y. Xie, Z. Li, W. Huang, J. Yuan, et al.Y. Liu. SOAPdenovo2: an empirically improved memory-efficient short-read de novo assembler. GigaScience.2012; 1:30-30.

36. K. Tamura, G. Stecher, D. Peterson, A. Filipski and S. Kumar. MEGA6: Molecular Evolutionary Genetics Analysis Version 6.0. Molecular Biology and Evolution.2013; 30:2725-2729.

37. D. M. Irwin, T. D. Kocher and A. C. Wilson. Evolution of the cytochromeb gene of mammals. Journal of Molecular Evolution.1991; 32:128-144.

Page $10 / 18$ 
38. M. Bernt, D. Merkle, K. Ramsch, G. Fritzsch, M. Perseke, D. Bernhard, et al.M. Middendorf. CREx: inferring genomic rearrangements based on common intervals. Bioinformatics.2007; 23:2957-2958.

39. K. Tyagi, R. Chakraborty, S. L. Cameron, A. D. Sweet, K. Chandra and V. Kumar. Rearrangement and evolution of mitochondrial genomes in Thysanoptera (Insecta). Scientific Reports.2020; 10:695.

40. K. Katoh and D. M. Standley. MAFFT Multiple Sequence Alignment Software Version 7: Improvements in Performance and Usability. Molecular Biology and Evolution.2013; 30:772-780.

41. J. Castresana. Selection of Conserved Blocks from Multiple Alignments for Their Use in Phylogenetic Analysis. Molecular Biology and Evolution.2000; 17:540-552.

42. Drummond A.J., Ashton B, Buxton S, Cheung M, Cooper A, Duran C, et al.Markowitz S. Geneious Ver 5.4. 2011.

43. A. Stamatakis. RAxML-VI-HPC: maximum likelihood-based phylogenetic analyses with thousands of taxa and mixed models. Bioinformatics.2006; 22:2688-2690.

44. F. Ronquist, M. Teslenko, P. V. Der Mark, D. L. Ayres, A. E. Darling, S. Hohna, et al.J. P. Huelsenbeck. MrBayes 3.2: Efficient Bayesian Phylogenetic Inference and Model Choice across a Large Model Space. Systematic Biology.2012; 61:539-542.

45. R. Lanfear, P. B. Frandsen, A. M. Wright, T. Senfeld and B. Calcott. PartitionFinder 2: New Methods for Selecting Partitioned Models of Evolution for Molecular and Morphological Phylogenetic Analyses. Molecular Biology and Evolution.2016; 34:772-773.

46. M. E. Alfaro. Bayes or Bootstrap? A Simulation Study Comparing the Performance of Bayesian Markov Chain Monte Carlo Sampling and Bootstrapping in Assessing Phylogenetic Confidence. Molecular Biology and Evolution.2003; 20:255-266.

47. D. M. Hillis and J. J. Bull. An Empirical Test of Bootstrapping as a Method for Assessing Confidence in Phylogenetic Analysis. Systematic Biology.1993; 42:182-192.

\section{Figures}




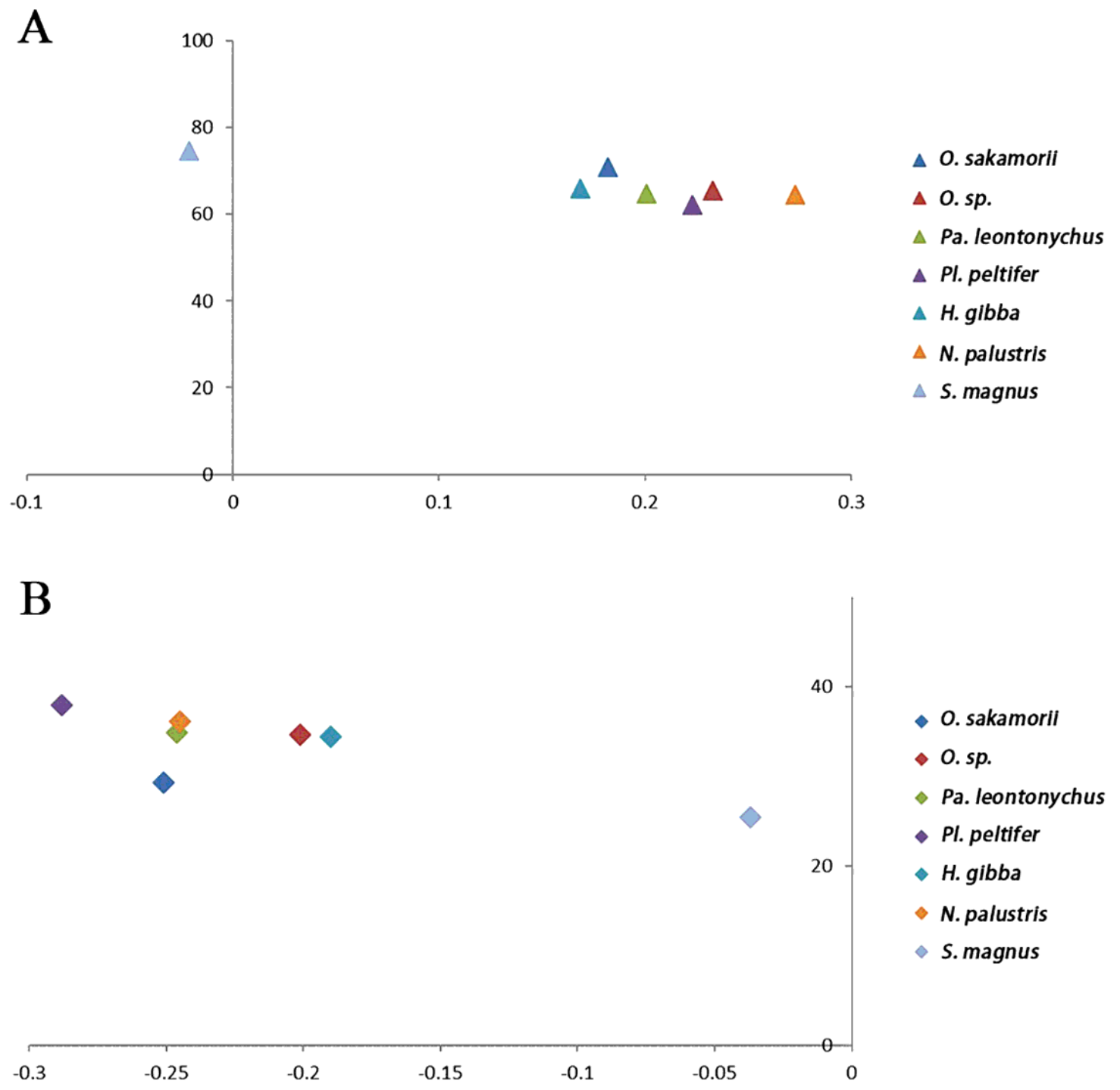

Figure 1

(A) AT\% vs AT-skew and (B) GC\% vs GC-skew are shown. Values are calculated on (-)-strands for full length mitochondrial genomes. X-axis shows level of nucleotide skew and the $\mathrm{Y}$-axis indicates the nucleotide percentages. 


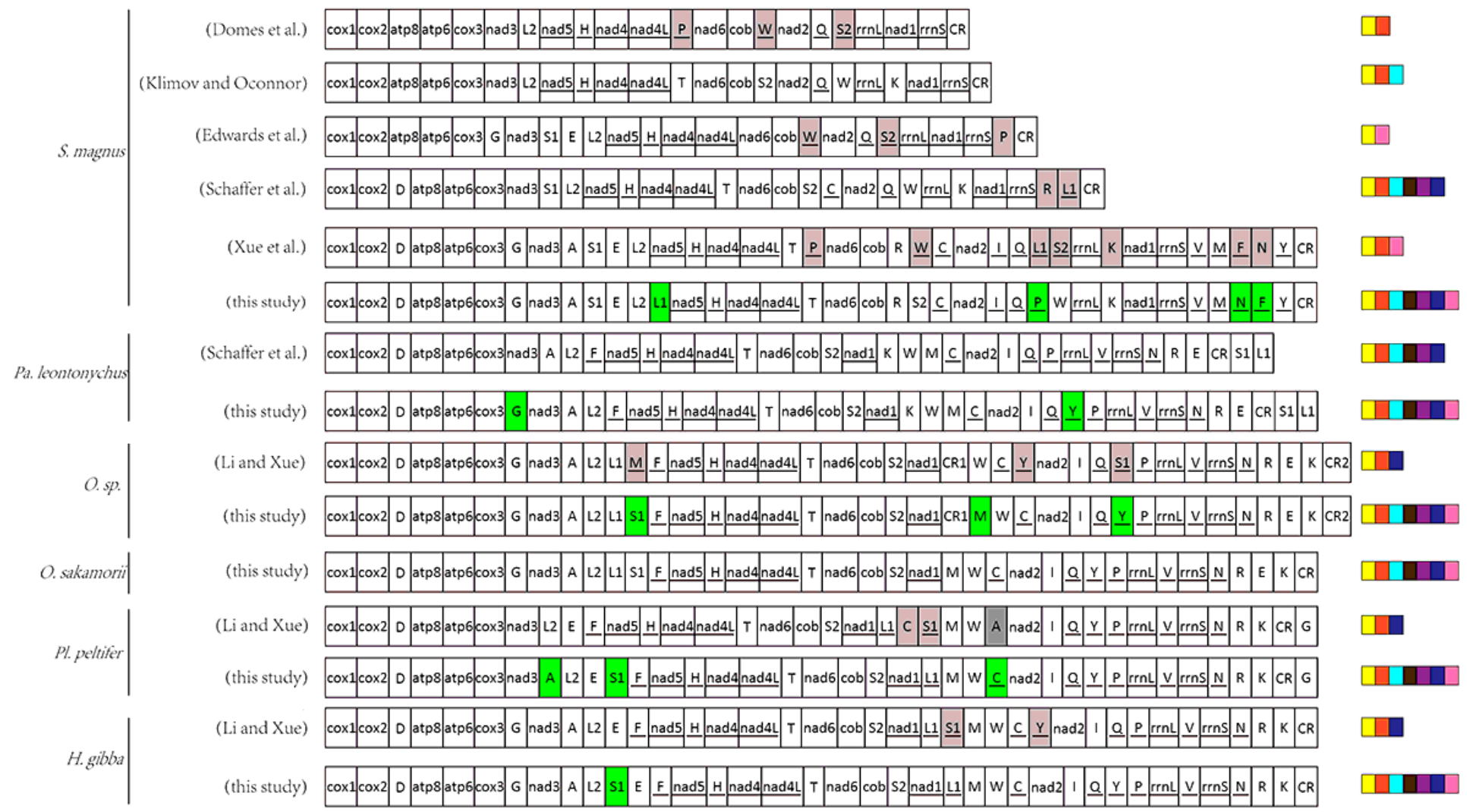

\section{Figure 2}

Mitochondrial gene orders of the six oribatid mite species. For S. magnus, Pa. leontonychus, O. sp., H. gibba and PI. peltifer, mitogenome orders obtained from different annotations are shown. Gray boxes represent that a gene was re-annotated. Green boxes highlight the newly predicted tRNAs. Underlined genes are on the (-)-strand. Genes are drawn in their original order; intergenic distances are not included and sizes of genes are not given according to scale. The tRNAs annotation methods are shown in different colors at the end of each sequence (tRANscan-SE in yellow, ARWEN in orange, Minimum free energy (MFE) in light blue, MITOS in black, MITOS2 in purple, manual annotation (anticodon and secondary structure) in blue, manual annotation (sequence alignments) in pink). 

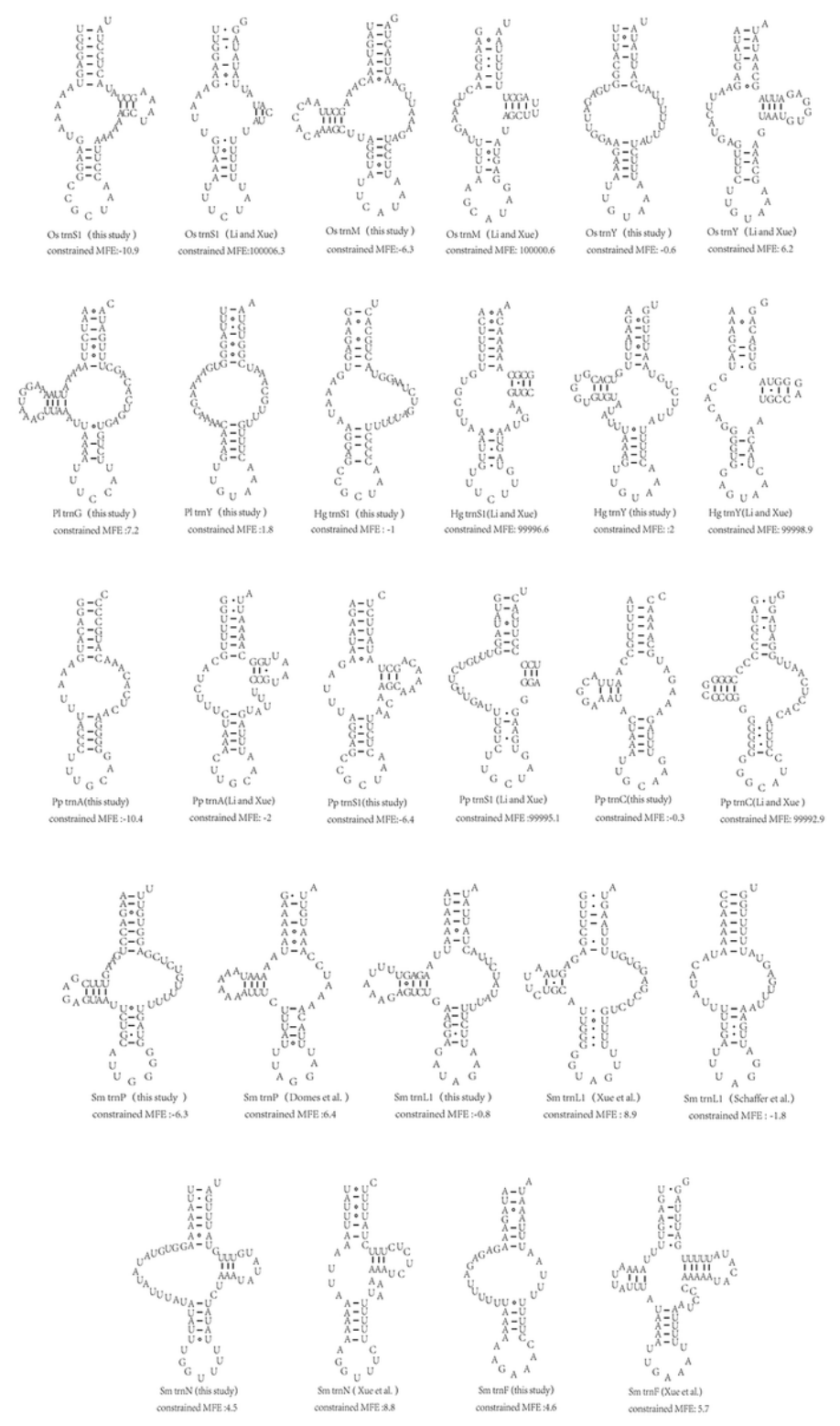

\section{Figure 3}

Comparison of the secondary structure of tRNAs. Pa. leontonychus $(\mathrm{PI})$ was retrieved two tRNAs. MFE indicate minimum free energy. 


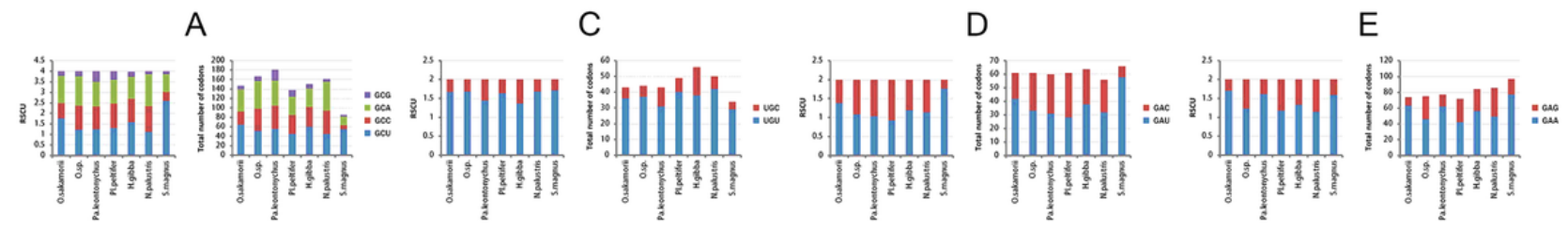

F

G

$\mathrm{H}$

I

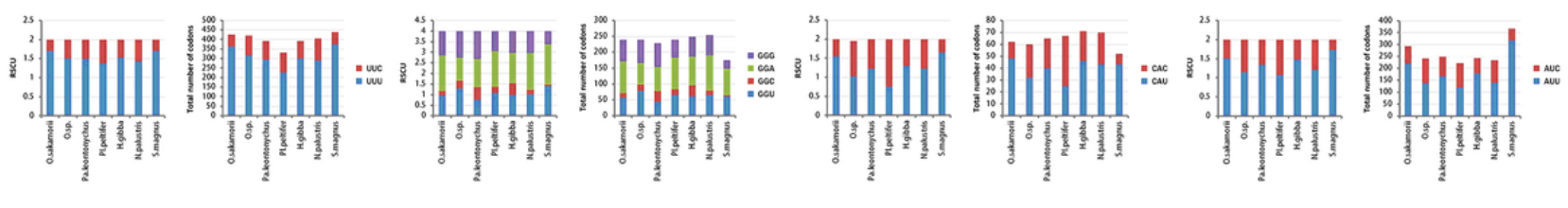

K

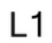

L2

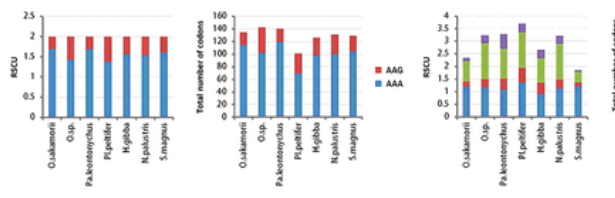

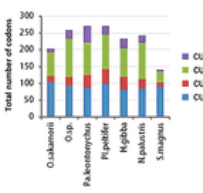

$\mathrm{N}$

P $\quad$ Q

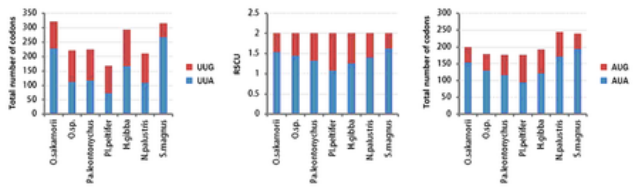

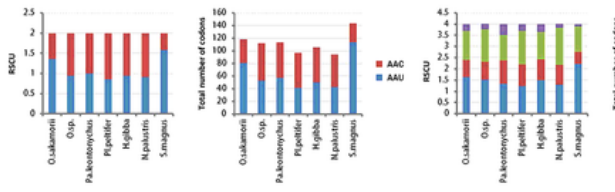

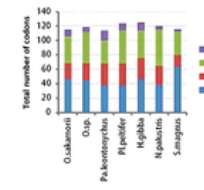

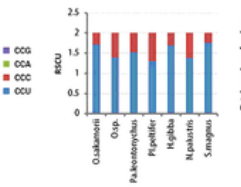

Q $\mathrm{R}$

S1

S2

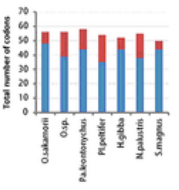

$\mathrm{R}$

W

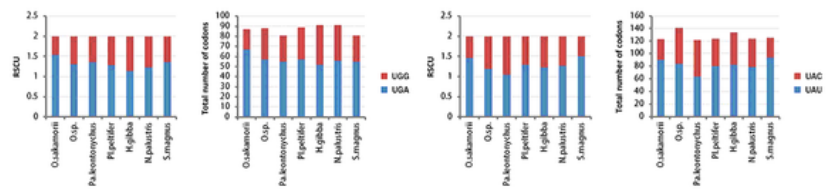

Figure 4

Relative synonymous codon usage (RSCU) and codon numbers of 22 amino acids. The X-axis indicates the oribatid mite species; the $\mathrm{Y}$ axis indicates the RSCU or total number of codons. 


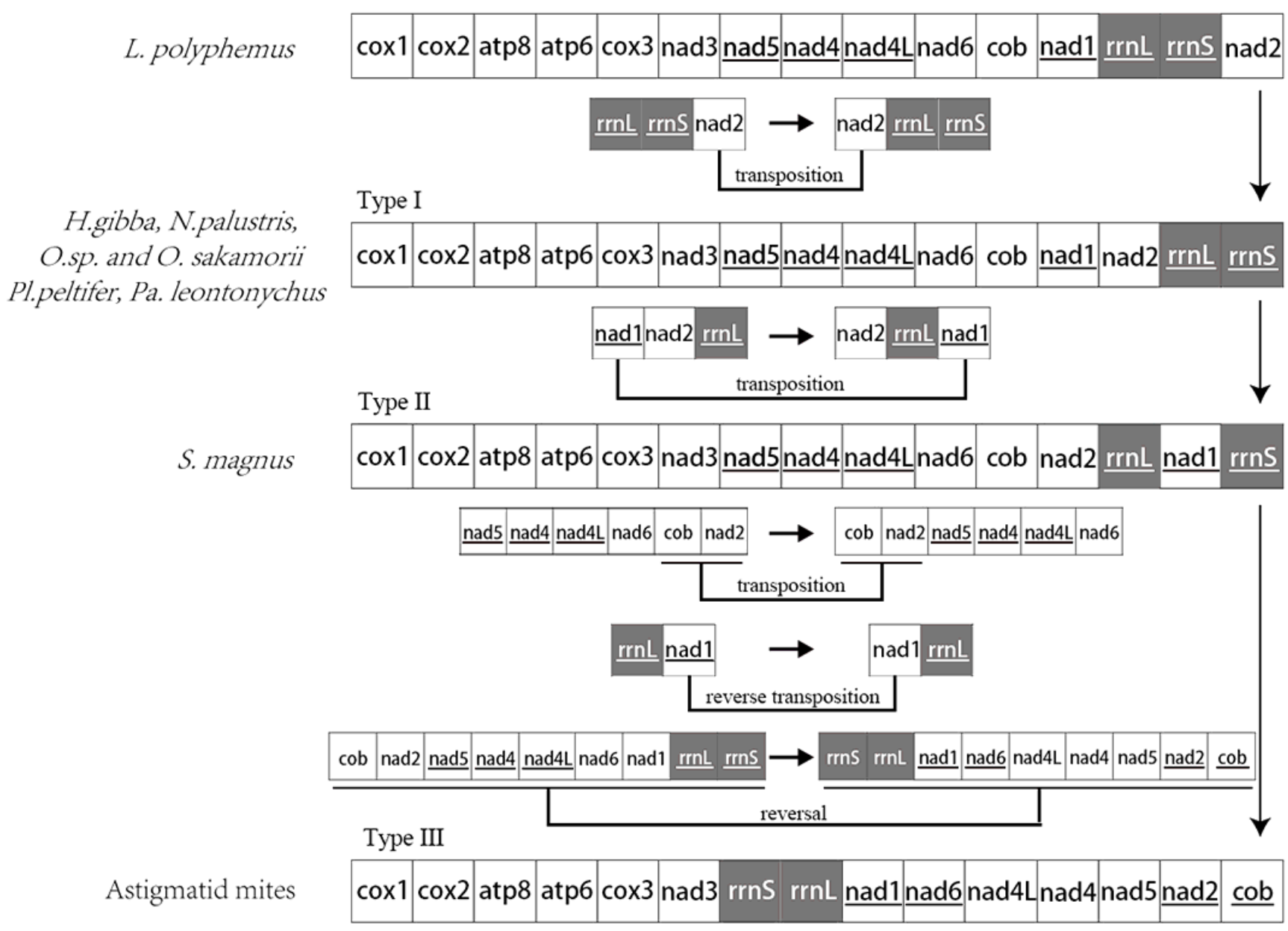

\section{Figure 5}

Evolution of gene orders (PCGs and rRNAs) in mt genomes explained by CREx. Rearrangement operations occurred from an inferred ancestral arthropod gene order to oribatid mites and then to astigmatid mites. Type I indicates mitochondrial PCGs and rRNAs gene order within six oribatid mites. Type II indicates mitochondrial PCGs and rRNAs gene order within S. magnus. Type III indicates mitochondrial PCGs and rRNAs gene order within astigmatid mites. Underlined genes are on the (-)-strand. Genes are drawn in their original order; intergenic distances are not included and sizes of genes are not true to scale. The rrnL and rrnS genes are color-coded (black gray in color). 


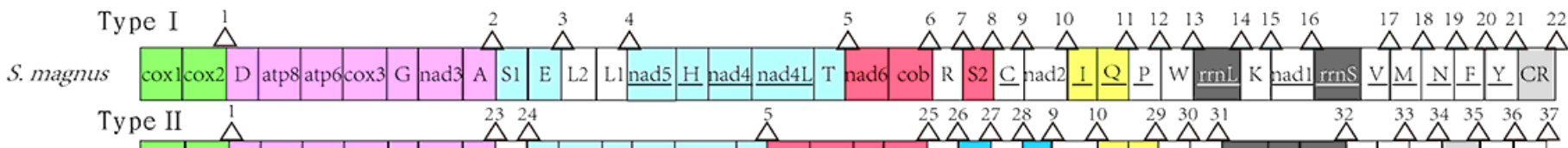

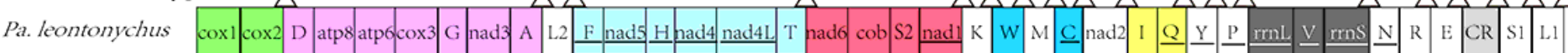

Type III $\triangle$

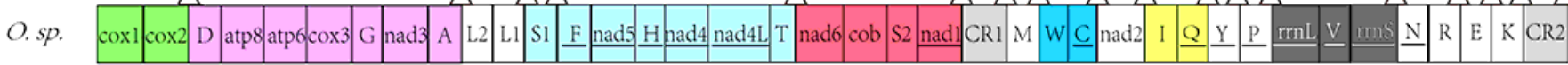

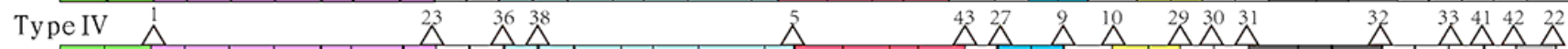

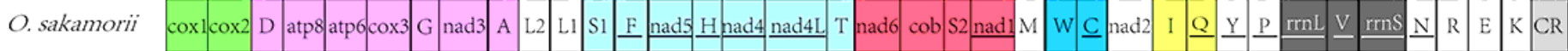

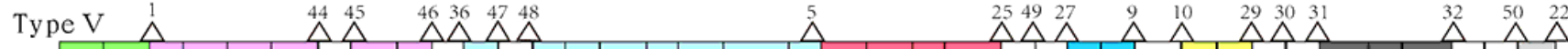

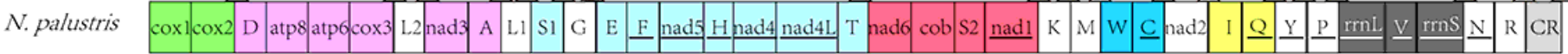
Type VI $\stackrel{1}{\triangle}$

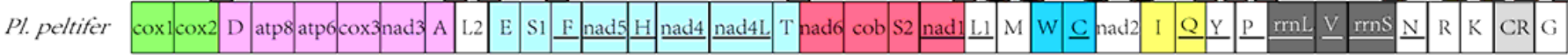

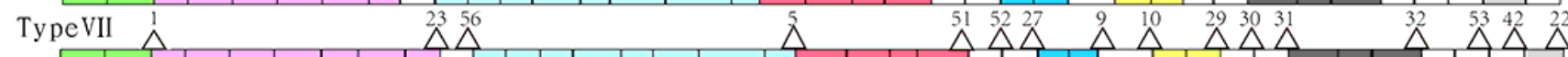

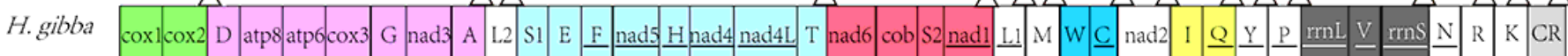

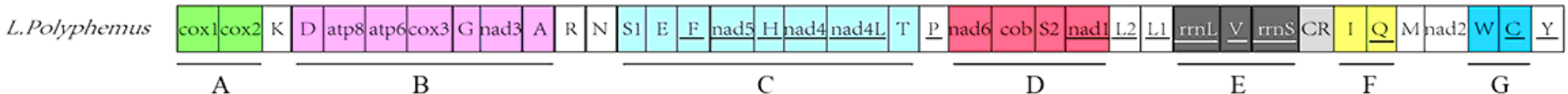

\section{Figure 6}

Gene order representation. Underlined genes are on the (-)-strand. Ancestral gene blocks A-G are underline in the L. polyphemus gene order and also indicated by different colors. Different codes were used to label the boundaries

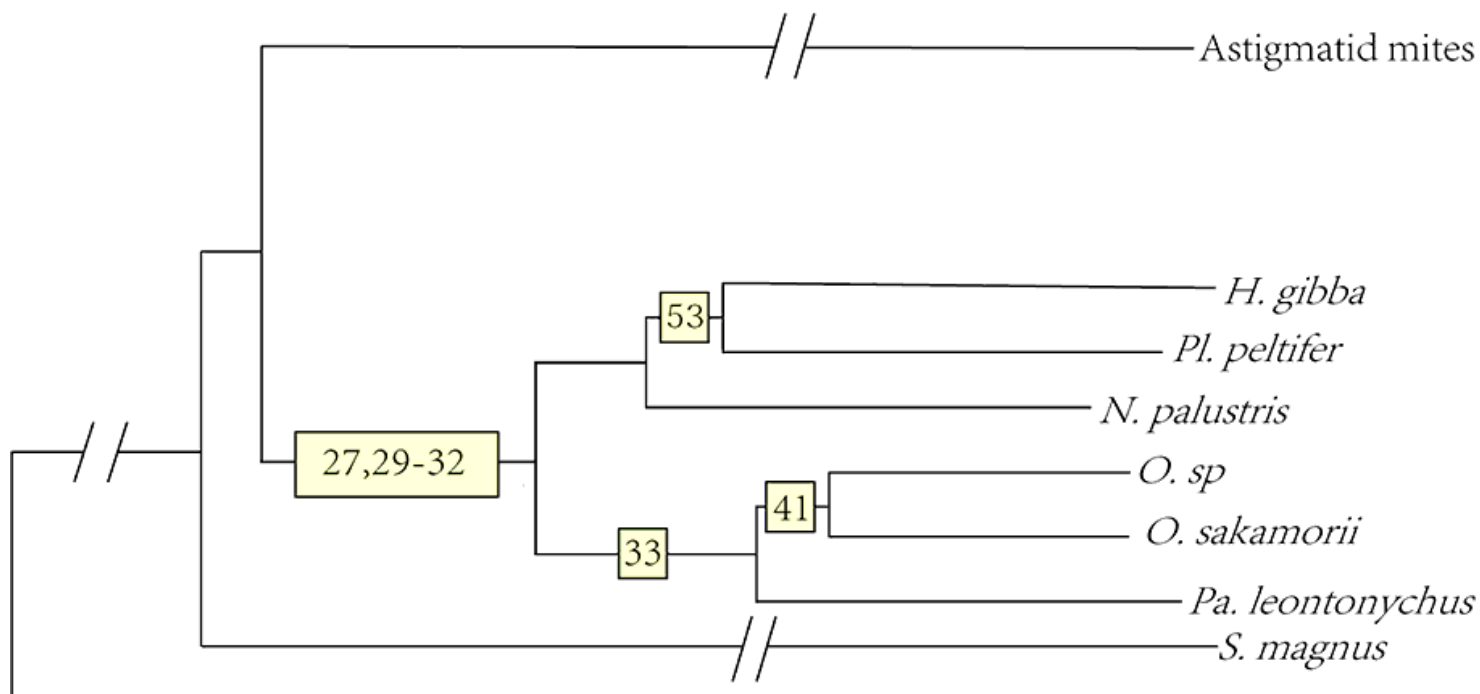

L. polyphemus

A B (C) D G F A B (C) D G F E (A) B* (C) D F E (A) B C* D G F E (A) B C (D) G F (A) B (C) D G F E (A) B (C) D - F E A B C DE F G

* indicate the gene found partially
(A) $\cos 1-\cos 2$
(E) $r r n L-V-r r n S$
27 M-W/W-M 32
rrnS-N
(B) D-atp8-atp6-cox3-G-nad3-A
(F) $I-Q$
(C) $\mathrm{S} 1-\mathrm{E}-\mathrm{F}-\mathrm{nad} 5-\mathrm{H}-\operatorname{nad} 4-\operatorname{nad} 4 \mathrm{~L}$
(G) $\mathrm{W}-\mathrm{C}$
29 Q-Y
33 R-E
(D) nad6-cob-S2-nad 1
31 P-rrnL 53 R-K 


\section{Figure 7}

Representation of derived characters on phylogenetic tree. Part of $\mathrm{BI}$ is used for representation of the ancestral and shared derived characters. Shared derived character states are shown on the node. Ancestral gene blocks $(A-G)$ are shown with different colors and code, which is shown at the terminal end of the branch. Partial ancestral characters are marked with an asterisk.

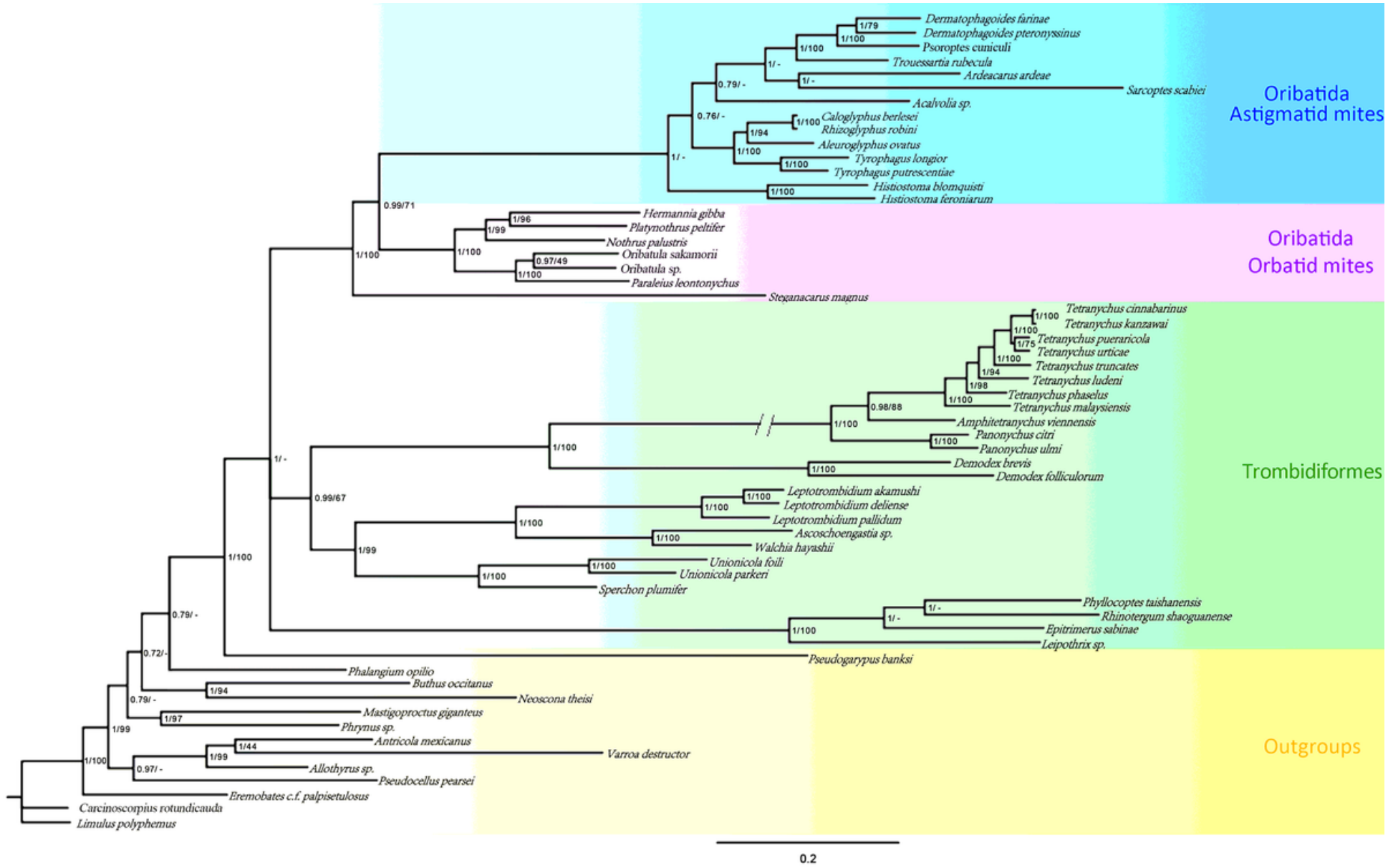

\section{Figure 8}

Phylogenetic tree inferred from mitochondrial genome sequences using maximum likelihood and Bayesian methods. Branch lengths presented here follow the Bayesian analysis. Node numbers indicate Bayesian posterior probabilities (BPP) and maximum likelihood bootstrap proportion (BSP). "-" indicates the absence of the node in corresponding analysis. The numbers indicate BPP and BSP values from analyses of datasets consisting of without third codon positions of PCGs.

\section{Supplementary Files}

This is a list of supplementary files associated with this preprint. Click to download.

- GraphicalAbstract.jpg

- TableS1.docx

- Tables2.docx

- TableS3.docx

- Figures1.tif 